\title{
ANÁLISE DA ATIVIDADE FLORESTAL NO MUNICÍPIO DE VIÇOSA-MG ${ }^{1}$
}

\author{
Alessandro Albino Fontes ${ }^{2}$, Márcio Lopes da Silva ${ }^{3}, S_{\text {Sebastião Renato Valverde }}^{3}$ e Agostinho Lopes de Souza ${ }^{3}$
}

\begin{abstract}
RESUMO - Estudou-se a atividade florestal no município de Viçosa-MG, a partir de questionário aplicado aos agricultores cujas propriedades rurais possuíam florestas plantadas. Foi amostrado um total de 63 propriedades rurais, abrangendo uma área de 2.096,95 ha. As áreas de floresta nativa e plantada, na amostra, foram de 372,00 e 260,17 ha, o que corresponde, respectivamente, a 17,74 e 12,41\% da área amostrada. O tipo de floresta nativa predominante foi a capoeira $(67,55 \%)$, e a espécie preferida para o reflorestamento foi o eucalipto $(92,68 \%)$. O uso médio da mão-de-obra nas fases de implantação, manutenção e colheita dos plantios florestais foi estimado em 30,21, 13,64 e 61,25 dias-homem/ha, respectivamente, totalizando 105,10 dias-homem/ha, sendo a participação da mão-de-obra familiar de $25,24 \%$. Os custos inerentes à atividade florestal foram estimados em $\mathrm{R} \$ 419,30 /$ ha para implantação; $\mathrm{R} \$ 146,49 /$ ha e $\mathrm{R} \$ 80,34 /$ ha para manutenção no primeiro e segundo ano, respectivamente; e $\mathrm{R} \$ 2,11 / \mathrm{m}^{3}$ para colheita da madeira. Os plantios florestais concentram-se nas áreas de encostas, e o número médio de empregos gerados pelo reflorestamento (eucalipto) foi 0,042 emprego/ha. Concluiu-se, de modo geral, que o reflorestamento é considerado atividade pouco atrativa, não identificando propriedades tipicamente florestais, sendo recomendada a elaboração de políticas públicas de incentivo ao reflorestamento.
\end{abstract}

Palavras-chave: Reflorestamento, eucalipto e propriedade rural.

\section{ANALYSIS OF FOREST ACTIVITY IN VIÇOSA-MG}

\begin{abstract}
Forest activity was studied in Viçosa-MG, through a questionnaire applied to farmers who planted forests. A total of 63 farms were sampled, comprising an area of 2,096.95 ha. The natural and planted forest areas sampled were of 372.00 ha and $260.17 \mathrm{ha}$, corresponding to $17.74 \%$ and $12.41 \%$, respectively. The predominant natural forest was the secondary forest (capoeira) (67.55\%), and the species chosen for reforestation was eucalypt (92.68\%). Average labor use in the phases of implementation, maintenance and harvest of the forest plantations was estimated at 30.21, 13.64 and 61.25 days-man/hectare, respectively, totalling 105.10 days-man/ hectare, with family labor participation of $25.24 \%$. Forest activity costs $(R \$ /$ ha $)$ were estimated at $R \$ 419.30$ for implementation; $R \$ 146.49$ and $R \$ 80.34$ for first and second year maintenance, respectively, and $R \$ 2.11 / \mathrm{m}^{3}$ for wood harvesting cost. The forest plantations are concentrated at the hillside areas and the average number of jobs generated by reforestation (eucalypt) was 0.042 jobs/hectare. It was concluded that, overall, reforestation was considered a rather unattractive activity, with typical forest properties remaining unidentified. Thus, it is recommended the elaboration of public policies to encourage reforestation.
\end{abstract}

Key words: Reforestation, eucalypt and farm.

\section{INTRODUÇÃO}

A destruição das florestas tropicais para implantação de projetos agropecuários, conduzidos com prejuízos ao ambiente, ocorreu e tem ocorrido com freqüência. Exemplo disto é a Zona da Mata de Minas Gerais, onde o seu processo de ocupação iniciou com a retirada das florestas, a partir do século XIX, para dar lugar à cultura

1 Recebido para publicação em 15.3.2002.

Aceito para publicação em 9.9.2003.

Apoio financeiro: CNPq e FAPEMIG.

2 Eng. Florestal, M.S., Doutorando em Ciência Florestal, Departamento de Engenharia Florestal da Universidade Federal de Viçosa -DEF/UFV, 36570-000 Viçosa-MG; ${ }^{3}$ Professor do Departamento de Engenharia Florestal da UFV. 
de café e, posteriormente, a pecuária, atividade esta muito exigente em área. Este processo foi determinante da quantidade, da qualidade e da distribuição espacial dos remanescentes florestais na Zona da Mata mineira (López, 1999).

As florestas desempenham um papel importante para a sociedade, proporcionando uma gama de benefícios, seja por meio dos seus produtos madeireiros ou nãomadeireiros, ou de suas múltiplas funções ecológicas e socioeconômicas, como a conservação da biodiversidade; a proteção dos recursos hídricos, edáficos e faunísticos; e a sua contribuição para o bem-estar social. Esses argumentos justificam a elaboração de uma política florestal nacional que concilie os objetivos de produção de madeira, preservação, conservação e geração de benefícios socioeconômicos (Schettino, 2000).

O Brasil, em 1999, possuía a maior área plantada com florestas de rápido crescimento, especialmente com os gêneros Eucalyptus e Pinus (4.805.930 ha). O eucalipto assumia a posição de destaque, com uma área total reflorestada de aproximadamente 2.965 .880 ha, sendo o Estado de Minas Gerais o maior reflorestador, com 1.535.290 ha, representando 51,77\% da área total reflorestada com Eucalyptus (SBS, 2000). Entretanto, para o município de Viçosa-MG, não se tem uma estatística recente sobre a área ocupada pelos reflorestamentos.

Diagnosticar o setor florestal é condição fundamental para estabelecer bases para uma gestão sustentada da atividade florestal. Somente por meio do conhecimento de dados e fatos reais podem ser elaborados planos e diretrizes que visem o desenvolvimento sustentado. Neste sentido, destacam-se os estudos desenvolvidos por Gonçalves (1959), Coelho (1999) e Schettino (2000), para o município e a microrregião de Viçosa, Minas Gerais, e para o Estado do Espírito Santo, respectivamente.

Os reflorestamentos com eucalipto apresentam viabilidade técnica e econômica, mostrando-se muito promissores. Essa espécie pode ampliar significativamente sua participação na composição da renda agropecuária, com vantagens adicionais sob a ótica social e ambiental (Costa et al.,1998). Constituem uma alternativa viável para áreas montanhosas, que, segundo Gonçalves (1959), abrangem cerca de $30,77 \%$ da área do município de Viçosa, que apresenta condições naturais favoráveis à realização de um programa florestal, além do fato de o relevo, o clima e as técnicas tradicionais de exploração de café, milho, arroz e feijão, principalmente, terem levado ao esgotamento das terras, refletindo, atualmente, nos baixos rendimentos culturais e nas pastagens degradadas.

Em face dessas considerações, este estudo buscou caracterizar a atividade florestal no município de ViçosaMG, levantando informações sobre as áreas de florestas das propriedades rurais, a localização dessas florestas em relação ao perfil topográfico, a mão-de-obra utilizada no reflorestamento, os custos inerentes a esta atividade, o consumo de madeira nas propriedades, a comercialização da madeira proveniente de reflorestamento e o fomento florestal existente no município.

\section{MATERIAL E MÉTODOS}

\section{1. Área de Estudo}

A área de estudo compreendeu as propriedades rurais com reflorestamento do município de Viçosa, região da Zona da Mata, sudeste do Estado de Minas Gerais, Brasil, cuja superfície total é de $279 \mathrm{~km}^{2}$ (27.900 ha) e sua sede possui latitude de $20^{\circ} 45^{\prime} 14^{\prime \prime} \mathrm{S}$ $(-20,753888889)$ e longitude de $42^{\circ} 52^{\prime} 53^{\prime \prime} \mathrm{W}$ $(-42,881388889)$ (GEOMINAS, 2000).

\subsection{Obtenção dos Dados}

A coleta dos dados foi realizada nos meses de julho a outubro de 2000, por meio da aplicação de questionário, em entrevista direta com os proprietários rurais sorteados na amostra.

O questionário buscou identificar o perfil da propriedade rural e do seu proprietário, os aspectos legais quanto à legislação florestal, a importância da atividade florestal, os principais mercados de produtos florestais, a assistência técnica, o uso dos recursos florestais e as perspectivas de plantios florestais.

\subsection{Método de Amostragem}

Na determinação do tamanho da amostra, ou seja, do número de propriedades rurais a serem amostradas, utilizou-se a metodologia adaptada por Little (1997), conforme o Quadro 1. O critério A, ou seja, o mais rigoroso, foi adotado para sugerir o tamanho mínimo da amostra, pelo fato de o número de agricultores reflorestadores no município de Viçosa-MG ser pequeno. 
Quadro 1 - Diretriz para seleção do tamanho da amostra Table 1 - Guideline for selection of sample size

\begin{tabular}{|c|c|c|c|}
\hline \multirow{2}{*}{$\begin{array}{c}\text { Tamanho da } \\
\text { População }\end{array}$} & \multicolumn{3}{|c|}{ Tamanho Mínimo para a Amostra Sugerido } \\
& \multicolumn{3}{|c|}{$(\%)$}
\end{tabular}

* A - mais rigoroso, B - mediamente rigoroso e C - menos rigoroso.

Obs. Essas porcentagens não implicam nenhum nível de confiança específico, mas pretendem ser apenas diretriz.

Fonte: adaptada por Little (1997).

A amostragem foi desenvolvida a partir de listagens de agricultores reflorestadores, fornecidas pelo escritório local do Instituto Estadual de Florestas de Minas Gerais (IEF-MG). Após a definição do número de propriedades rurais a serem amostradas, procedeu-se ao sorteio aleatório daquelas onde seriam realizadas as entrevistas.

Para entendimento do trabalho, as propriedades rurais estudadas foram agrupadas em quatro estratos, quais sejam: estrato I, de 0 - 20 ha; estrato II, de 20 50 ha; estrato III, de 50 - 100 ha; e estrato IV, maiores que 100 ha. O tamanho mínimo da amostra foi determinado em 50 propriedades rurais a serem estudadas (Quadro 2).

Quadro 2 - Tamanho mínimo sugerido para a amostra Table 2 - Minimum size suggested for the sample

\begin{tabular}{|c|c|c|}
\hline Estrato & Propriedades Levantadas* & Tamanho da Amostra** \\
\hline I & 82 & 21 \\
\hline II & 34 & 17 \\
\hline III & 10 & 10 \\
\hline IV & 2 & 2 \\
\hline Total & 128 & 50 \\
\hline
\end{tabular}

* Amostragem com base na diretriz para seleção do tamanho da amostra (Little, 1997). Listagens de agricultores reflorestadores fornecidas pelo Escritório Local do IEF-MG.

**Amostragem com base na diretriz para seleção do tamanho da amostra (Little, 1997).

\subsection{Caracterização da Propriedade Rural}

O questionário aplicado levantou informações sobre o entrevistado, a propriedade rural e a atividade florestal, conforme Fontes (2001). A partir dessas informações foi possível estabelecer o perfil do agricultor e da propriedade.

Para a atividade florestal, foram levantadas informações sobre as florestas nativas e plantadas existentes na propriedade, as razões para a realização do plantio de florestas, as expectativas quanto ao reflorestamento, as espécies preferenciais, os empregos gerados, os salários pagos, os custos inerentes à atividade, o consumo e a venda de madeira, o mercado madeireiro, os preços praticados, as condições e os tipos de venda, a participação em programas de fomento e incentivos governamentais, o acesso às informações ou orientações técnicas e a realização de desmatamentos na propriedade. Essas informações permitiram caracterizar a atividade florestal no município.

\subsection{Análise dos Dados}

Os dados foram avaliados por meio da análise tabular. Essa técnica, segundo Mata (1994), citado por Schettino (2000), facilita a compreensão de dados qualitativos e permite a descrição pormenorizada das variáveis estudadas.

A estimativa dos custos de produção para o reflorestamento foi realizada a partir das informações levantadas no questionário, considerando os custos de implantação, manutenção, colheita e condução de brotação.

Para o cálculo do número médio de empregos gerados, utilizou-se como base uma jornada de trabalho de 24 dias por mês (288 dias/ano).

\section{RESULTADOS E DISCUSSÃO}

Foi aplicado um total de 63 questionários aos produtores rurais do município de Viçosa, sendo 27 no estrato I, 24 no estrato II, 10 no estrato III e 2 no estrato IV.

\subsection{Características Gerais do Proprietário e da Propriedade}

Do total de entrevistados, $90,48 \%$ são do sexo masculino e a idade média foi de 62,98 anos. Quanto ao nível de escolaridade, 7,94\% são analfabetos; a maioria

R. Árvore, Viçosa-MG, v.27, n.4, p.517-525, 2003 
$(55,56 \%)$ concluiu apenas o primário; $6,35 \%$ o $1^{\circ}$ grau; $14,29 \%$ o $2^{\circ}$ grau; e $15,87 \%$ o nível superior, sendo $70 \%$ deste com pós-graduação.

Quanto à ocupação principal e fonte de renda, $33,33 \%$ dos entrevistados trabalham somente na sua propriedade rural; 7,94\% são assalariados fora da propriedade; $1,59 \%$ são trabalhadores autônomos; e a grande maioria $(57,14 \%)$ é aposentada ou pensionista. Cabe ressaltar que muitos agricultores aposentados continuam trabalhando na sua propriedade. Observou-se também que, quanto maior o tamanho da propriedade, maior é a tendência de se obter a renda somente da propriedade.

As 63 propriedades rurais amostradas localizam-se, em média, a 9,71 km da sede do município. A área total amostrada foi de $2.096,95 \mathrm{ha}$, correspondendo a $12,07 \%$ da área rural e a 7,52\% da área total do município.

De acordo com as informações sobre a forma de aquisição da propriedade rural, constata-se que a maior parte das propriedades amostradas $(61,90 \%)$ foi comprada e $38,10 \%$ herdada, não tendo sido observado nenhum caso de arrendamento ou assentamento. O tempo médio de exercício de atividades na propriedade rural foi de 27 anos.

No ano agrícola de 1999, 9,52\% dos proprietários rurais entrevistados fizeram uso de crédito agrícola na propriedade; $36,51 \%$ receberam algum tipo de assistência técnica; e $84,13 \%$ contrataram mão-de-obra, sendo a mão-de-obra braçal a forma mais comum. Observou-se que o uso de crédito agrícola e de assistência técnica é proporcional ao tamanho da propriedade.

$\mathrm{O}$ valor médio encontrado para o hectare de terra nua, sem benfeitorias, no município de Viçosa, segundo informações dos agricultores, foi de $\mathrm{R} \$ 3.058,00 /$ ha. Após contatos com alguns corretores de imóveis rurais, verificou-se que esse valor encontrava-se superestimado. Observou-se que o valor do hectare de terra nua é inversamente proporcional ao tamanho da propriedade.

\subsection{A atividade Florestal}

\subsection{1. Área Florestal das Propriedades}

O Quadro 3 mostra a área florestal total e média estimada no município de Viçosa-MG, em 1999. A partir destes dados foram obtidos os porcentuais florestais, em função da área amostrada, como sendo de $17,74 \%$ para a floresta nativa e $12,41 \%$ para a floresta plantada, sendo $30,15 \%$ o porcentual florestal total.

Esse porcentual florestal nativo estimado $(17,74 \%)$ diverge dos estimados por Gonçalves (1959) (10,77\%), Coelho (1999) (27,28\%) e Pereira (1999) (26,29\%). Uma explicação para o fato seria a metodologia utilizada pelos dois últimos, que se baseou em fotografias aéreas, portanto com pouca capacidade para distinguir florestas nativas de plantadas. Tal fato foi comprovado pelo baixo porcentual encontrado para estas últimas. Entretanto, analisando a área florestal total (nativa + plantada), os valores obtidos neste estudo foram superiores aos encontrados por Coelho (1999) e Pereira (1999). A diferença com relação ao porcentual estimado por Gonçalves (1959) pode ser explicada pelo declínio das atividades agropecuárias tradicionais na região, como o café; pelas exigências da legislação trabalhista com relação ao trabalhador rural; e pelo maior rigor das leis florestais e ambientais, o que contribuiu para o aumento da área florestal no município.

De acordo com a legislação florestal vigente, todo imóvel rural deve ter uma cobertura florestal adequada e que atenda aos preceitos ambientais e legais denominada

rea florestal estimada no município de Viçosa-MG, em 1999

Table 3 - Estimated forest area in Viçosa-MG, in 1999

Quadro 3 - Á

Área da Propriedade (ha) Área de Floresta Nativa (ha) Área de Floresta Plantada (ha) Árestal (ha)

\begin{tabular}{|c|c|c|c|c|c|c|c|c|}
\hline \multirow{2}{*}{ Estrato } & \multicolumn{2}{|c|}{} & \multicolumn{2}{|c|}{} & \multicolumn{2}{|c|}{ Média } \\
\cline { 2 - 9 } & Total & Média & Total & Média & Total & Média & Total & 3,44 \\
\hline I & 288,25 & 10,68 & 36,10 & 1,34 & 56,72 & 2,10 & 92,82 & 10 \\
\hline II & 774,60 & 32,28 & 128,90 & 5,37 & 115,28 & 4,80 & 244,18 & 10,17 \\
\hline III & 640,10 & 64,01 & 127,00 & 12,70 & 52,67 & 5,27 & 179,67 & 17,97 \\
\hline IV & 394,00 & 197,00 & 80,00 & 40,00 & 35,50 & 17,75 & 115,50 & 57,75 \\
\hline Amostra & $2.096,95$ & $33,28^{*}$ & 372,00 & $5,90 *$ & 260,17 & $4,13^{*}$ & 632,17 & $10,03 *$ \\
\hline
\end{tabular}

* Média geral.

R. Árvore, Viçosa-MG, v.27, n.4, p.517-525, 2003 
de reserva legal, que na região centro-sul do País corresponde a $20 \%$ da área total da propriedade. No entanto, para as pequenas propriedades, área menor que 50 ha, e para aquelas propriedades onde a área de preservação permanente representa mais de $50 \%$ do total da propriedade, a lei permite alocar esta reserva legal em área de preservação e outras, conforme autorização do órgão competente (Brasil, 1965; Minas Gerais, 1995). Desta forma, observa-se que os estratos I e II atendem à legislação florestal quanto à exigência desta reserva. Porém, para os demais extratos (III e IV) estes estão em desacordo com a lei.

Procurou-se levantar também as áreas de floresta nativa existente, por estádio de vegetação florestal (Quadro 4). Pelos resultados obtidos, constatou-se o predomínio das formações florestais secundárias (capoeirão, capoeira e capoeirinha) em todos os estratos estudados. A mata primária se fez presente somente no estrato II, representando menos de $1 \%$ em relação à amostra, em razão do elevado desmatamento para o plantio de café e milho, que posteriormente foram abandonados, transformando essas áreas em matas secundárias.

Os 3,0 ha de mata primária detectados na amostra (Quadro 4) estão localizados, em relação ao perfil topográfico, no topo do morro.

Com relação às florestas secundárias, observou-se maior concentração das áreas florestais nativas no terço superior $(75,46 \%)$, em decorrência do modelo de uso do solo empregado na região. Do total dessas matas, $11,48 \%$ estão localizadas no terço médio, $3,52 \%$ no terço inferior e 9,54\% nos topos de morros. As áreas mais amorradas, ou seja, com declividades mais acentuadas, são mantidas com cobertura florestal natural, uma vez que são de difícil manejo, não permitindo ou dificultando outros usos.
Outro fato que se observou é a inexistência de matas em áreas de várzea, áreas estas preferidas para cultivos agrícolas como milho, feijão, olericultura e fruticultura.

Quanto aos reflorestamentos, observa-se, em média, que as áreas mais planas, como as várzeas (3,89\%), e os topos de morros $(4,52 \%)$ são pouco utilizados para os plantios florestais, que se concentram nas áreas de encosta, distribuindo-se de maneira mais ou menos uniforme nos terços inferior $(21,90 \%)$, médio $(40,08 \%)$ e superior (29,60\%), com uma leve predominância no terço médio.

\subsubsection{Ocupação do Solo e Atividade de Reflorestamento}

No presente estudo, constatou-se que o reflorestamento com eucalipto e pinus corresponde a $12,41 \%$ ( 260,17 ha) da área compreendida pela amostra. O eucalipto é a espécie de maior interesse dos agricultores ocupando 92,68\% (241,13 ha) desta área. Da área reflorestada com eucalipto, 63,09\% (152,14 ha) encontrase em regime de alto fuste; $32,40 \%(78,11 \mathrm{ha}) \mathrm{em}$ primeira talhadia; e $4,51 \%$ ( $10,88 \mathrm{ha}$ ) em segunda talhadia.

A implantação dos reflorestamentos ocupou áreas de pastagens (54,55\% dos casos); abandonadas e, ou, inaproveitáveis para cultivo $(19,70 \%)$; de café $(15,15 \%)$; capoeiras $(7,58 \%)$; e culturas anuais $(3,03 \%)$. Tal situação demonstra que o reflorestamento no município de Viçosa pouco compete com a produção de alimentos básicos.

Observou-se que o reflorestamento e as pastagens são concorrentes em área, podendo ser explicado pela decadência da pecuária bovina na região. Já a competição com a cultura de café, a substituição ocorreu em lavouras decadentes.

Quadro 4 - Distribuição da área florestal quanto ao tipo de floresta nativa, no município de Viçosa-MG, ano de 1999 Table 4 - Distribution of the forest area regarding type of native forest, in Viçosa-MG, 1999

\begin{tabular}{|c|c|c|c|c|c|c|c|c|c|c|}
\hline \multirow{2}{*}{ Estrato } & \multicolumn{2}{|c|}{ Mata Primária } & \multicolumn{2}{c|}{ Capoeirão } & \multicolumn{2}{c|}{ Capoeira } & \multicolumn{2}{c|}{ Capoeirinha } & \multicolumn{2}{c|}{ Total } \\
\cline { 2 - 12 } & (hectare) & $(\%)$ & (hectare) & $(\%)$ & (hectare) & $(\%)$ & (hectare) & $(\%)$ & (hectare) & $(\%)$ \\
\hline I & --- & --- & 1,00 & 2,77 & 23,30 & 64,54 & 11,80 & 32,69 & 36,10 & 100,00 \\
\hline II & 3,00 & 2,33 & 15,00 & 11,64 & 69,00 & 53,53 & 41,90 & 32,51 & 128,90 & 100,00 \\
III & --- & --- & 28,00 & 22,05 & 79,00 & 62,20 & 20,00 & 15,75 & 127,00 & 100,00 \\
\hline IV & --- & --- & --- & --- & 80,00 & 100,00 & --- & --- & 80,00 & 100,00 \\
\hline Amostra & 3,00 & $0,81^{*}$ & 44,00 & $11,83^{*}$ & 251,30 & $67,55^{*}$ & 73,70 & $19,81^{*}$ & 372,00 & 100,00 \\
\hline
\end{tabular}

* Média geral. 
Quanto às perspectivas de futuros plantios florestais, essa tendência parece se sustentar. As áreas atualmente ocupadas por pastagens mantiveram-se na preferência dos agricultores (66,67\% dos casos), seguidas das áreas abandonadas e, ou, inaproveitáveis para cultivo agrícola $(11,11 \%)$. Para as demais áreas as expectativas são: culturas anuais $(5,56 \%)$, cultivo de café $(5,56 \%)$ e outras áreas $(11,12 \%)$.

Quanto às atividades de reflorestamento, observouse a existência de inúmeras técnicas na implantação, mas com predomínio de duas delas, que consistem em roçar, queimar e covear (21,88\% dos casos) e em coroar e covear (21,88\% dos casos). Essas técnicas, embora uma envolva o uso do fogo, evitam o revolvimento do solo, o que em relevo acidentado, típico da região, pode trazer prejuízos ambientais, como erosão, lixiviação etc.

Inúmeros foram os espaçamentos utilizados pelos agricultores em reflorestamentos com eucalipto, predominando o $2 \times 2$ ( $23,81 \%$ dos casos), seguido do espaçamento $3 \times 2(15,87 \%)$. De modo geral, observou-se a preferência dos agricultores por plantios mais adensados. Pôde-se constatar que os proprietários rurais nem sempre optam pelos espaçamentos sugeridos pelos técnicos dos órgãos de fomento florestal.

Os motivos que levam os agricultores a realizarem reflorestamentos em suas propriedades e as expectativas quanto à atividade são informações importantes para balizar políticas públicas de incentivo a plantios florestais com agricultores. Como principais razões da realização de reflorestamentos os agricultores pesquisados citaram: abastecimento da propriedade (54,69\% dos casos); aumento da renda familiar (21,88\%); aproveitamento de áreas ociosas $(7,81 \%)$; embelezamento da propriedade $(3,13 \%)$; aspectos conservacionistas $(3,13 \%)$; e outros motivos $(9,38 \%)$. Nota-se que a adoção do reflorestamento para fins conservacionistas é atitude pouco comum.

Com relação às expectativas quanto ao reflorestamento com eucalipto e pinus, menos de $2 \%$ dos agricultores amostrados pretendem encerrar a atividade. A grande maioria $(73,01 \%)$ quer manter suas áreas reflorestadas no tamanho em que se encontram, enquanto $25,40 \%$ pretendem ampliá-las. A área média que estes últimos dedicariam aos novos cultivos seria de 2,49 ha. Esses resultados indicam a garantia de suprimento de madeira na propriedade e o atendimento a uma parte do consumo de serrarias e afins, acarretando uma diminuição da pressão sobre os remanescentes florestais nativos.

R. Árvore, Viçosa-MG, v.27, n.4, p.517-525, 2003
Constatou-se que os agricultores mostraram-se pouco interessados (somente 14,29\%) em plantar ou recuperar áreas com outras espécies florestais, o que significa pouca preocupação com os aspectos conservacionistas e preservacionistas.

Quanto às causas para não prosseguir na atividade florestal, ou seja, não-realização de novos plantios com eucalipto, observou-se que a maioria dos pequenos proprietários (estrato I) apontou a indisponibilidade de terra. Já os proprietários do estrato IV alegaram ser a atividade pouco rentável. De modo geral, a disponibilidade de terra foi a principal causa para não prosseguir na atividade florestal (34,04\% dos casos); seguida de recursos financeiros, mão-de-obra, atividade pouco rentável e idade avançada do proprietário, com $10,64 \%$ cada; dificuldade em obter permissão para exploração florestal no IEF, terreno em inventário (partilha) e outros projetos, com $4,26 \%$ cada; e outras causas $(8,51 \%)$. Um fato curioso é que a formiga, uma das principais pragas florestais, teve pouca relevância na opinião dos agricultores estudados $(2,13 \%)$.

\subsubsection{Mão-de-Obra Utilizada no Reflorestamento}

O uso da mão-de-obra nos reflorestamentos com eucalipto na área em estudo tem sido muito intensivo. Em geral são necessários 105,10 dias-homem por hectare reflorestado (d-h/ha), desde a implantação, 30,21 d-h/ha $(28,74 \%)$, passando pela manutenção, $13,64 \mathrm{~d}-\mathrm{h} / \mathrm{ha}$ (12,98\%), até a colheita, $61,25 \mathrm{~d}-\mathrm{h} / \mathrm{ha}(58,28 \%)$. Apesar de ser uma fase semimecanizada, a colheita tem sido a mais exigente em mão-de-obra.

Estimou-se que a mão-de-obra familiar representa, em média, $31,25 \%$ da mão-de-obra utilizada na fase de implantação, $28,15 \%$ na manutenção e $21,63 \%$ na colheita, com uma média geral de $25,24 \%$ em relação à mão-de-obra total. Em todas as fases do reflorestamento, observou-se que o uso da mão-de-obra familiar é mais intensa no estrato I, decrescendo nos demais.

A quantificação do uso da mão-de-obra na fase de colheita dos povoamentos florestais foi tarefa difícil, o que fez com que gerasse um baixo volume de informações. Constatou-se, de modo geral, que os agricultores não participam diretamente dessa fase, uma vez que a venda da madeira em pé é prática comum, e quando o próprio agricultor utiliza a madeira de reflorestamento em sua propriedade ele realiza corte seletivo. O corte raso do povoamento, geralmente, é realizado por terceiros. 
Constatou-se também que a atividade de condução de brotação é prática pouco utilizada pelos agricultores. Em média, essa atividade consome 6,75 d-h/ha, tendo a mão-de-obra familiar grande participação $(62,96 \%)$.

A remuneração da mão-de-obra apresentou variações de uma região para outra, embora o seu valor não tenha se diferenciado em função do tamanho da propriedade. $\mathrm{O}$ valor médio constatado para a diária ( 8 horas/ dia), no ano agrícola de 1999, foi de R \$7,62 dia/homem. Considerando uma jornada de trabalho de 24 dias/mês, tem-se um salário mensal de $\mathrm{R} \$ 182,88$ (não inclui encargos sociais). Observou-se que o valor desta diária não diferiu nas fases do reflorestamento.

\subsubsection{Custos na Atividade Florestal}

A atividade de reflorestamento tem sido extremamente diversificada quanto à tecnologia empregada, o uso de mão-de-obra e, principalmente, às técnicas de cultivo empregadas, o que torna a quantificação dos custos uma tarefa difícil. Desta forma, procurou-se apresentar, de maneira simplificada, os custos médios estimados. Os custos de manutenção do povoamento foram divididos em primeiro e segundo ano, por serem os do segundo ano menores que os do primeiro.

O custo médio de implantação foi estimado em $\mathrm{R} \$ 419,30 /$ ha; os de manutenção no primeiro e segundo ano em $\mathrm{R} \$ 146,49 /$ ha e $\mathrm{R} \$ 80,34 /$ ha, respectivamente; o custo de colheita em $\mathrm{R} \$ 2,11 / \mathrm{m}^{3}$; e o custo de condução de brotação em $\mathrm{R} \$ 58,00 /$ ha. O custo de colheita apresentado engloba as operações de abate, desgalhamento, traçamento e embandeiramento ou empilhamento, quando o serviço é remunerado por produção.

\subsubsection{Consumo de Madeira na propriedade}

De acordo com as informações dos agricultores entrevistados, o consumo médio de madeira na propriedade foi de 11,65 m³/ano. Do total consumido, 71,46\% provém de florestas plantadas. Este fato é compreensível e ao mesmo tempo previsível, pois, como relatado anteriormente, 54,69\% deles realizaram reflorestamento com o intuito de usar a madeira na propriedade.

Observou-se uma certa tendência de crescimento do consumo de madeira, tanto de floresta plantada como de nativa, para fins energéticos (lenha), mourões e construções rurais, com o aumento do tamanho da propriedade. De modo geral, este consumo tende a se elevar com o aumento do tamanho da propriedade, principalmente para as duas do estrato IV, para uso na secagem de café e pasteurização do leite.

O principal uso dessa madeira tem sido para fins energéticos $(65,74 \%)$, seguido de mourões $(17,57 \%)$, construções rurais $(8,72 \%)$, serraria $(4,29 \%)$, escoras $(1,29 \%)$ e outros $(1,36 \%)$.

\subsubsection{A Comercialização da Madeira de Reflorestamento}

Em 1999, apenas 20,63\% dos proprietários rurais entrevistados venderam madeira proveniente de reflorestamento, em suas propriedades. Seus principais compradores foram: pequenas serrarias $(21,43 \%)$, indústria de móveis $(14,29 \%)$, intermediários $(14,29 \%)$, outros agricultores (14,29\%), revendedores de escoras $(14,29 \%)$ e outros compradores $(21,43 \%)$.

Na maioria dos casos $(61,54 \%)$, a condição de pagamento da madeira foi à vista e o custo de transporte pago pelo comprador. Nos demais $38,46 \%$, o custo do transporte foi incluído no preço.

De modo geral, a madeira proveniente de reflorestamentos foi vendida em pé $(69,23 \%$ dos casos), colhida pelo agricultor $(23,08 \%)$, e colhida e transportada pelo agricultor $(7,69 \%)$.

Não houve grandes diferenças quanto à localização do comprador dessa madeira, predominando aqueles localizados fora do município (38,46\% dos casos), em geral pequenas serrarias que revendem essa madeira, na forma de sarrafos, para a indústria moveleira de Ubá; na sede do município ( $30,77 \%$ ); e na comunidade do agricultor $(30,77 \%)$.

Quanto ao preço da madeira, na maioria das vezes $(53,85 \%)$ este foi definido pelo agricultor (produtor), pelo comprador $(30,77 \%)$ e de outras formas $(15,38 \%)$, sempre com base no preço de mercado. Tal procedimento mostra o poder de barganha do produtor na comercialização do produto, talvez pelo fato de a oferta desse tipo de madeira no município ser pequena.

\subsubsection{O Fomento Florestal}

A maioria dos proprietários rurais amostrados $(86,89 \%)$ participou de programas de fomento florestal. O principal órgão responsável pelo fomento florestal no município foi o IEF-MG (74,55\% dos casos), seguido

R. Árvore, Viçosa-MG, v.27, n.4, p.517-525, 2003 
da EMATER-MG (14,55\%), UFV (3,64\%), União Reflorestamento $(3,64 \%)$ e Matarazzo $(1,82 \%)$.

Segundo esses agricultores, $61,67 \%$ receberam informações ou orientação técnica sobre a atividade florestal. Como origem dessa assistência técnica, o IEFMG foi citado em $71,79 \%$ dos casos, seguido da EMATER-MG (15,38\%). Observa-se que o IEF-MG aparece como principal órgão de fomento e assistência técnica florestal do município de Viçosa-MG.

Embora 86,89\% dos proprietários amostrados tenham participado de programas de fomento florestal, apenas $61,67 \%$ afirmaram ter recebido informações ou orientações técnicas sobre a atividade, revelando que, algumas vezes, o agricultor realiza o reflorestamento à sua própria maneira.

Dentre as práticas silviculturais repassadas para o agricultor recebeu orientação, destacam-se as relacionadas à implantação do povoamento, como: espaçamento $(25,95 \%)$, preparo do terreno $(23,66 \%)$, combate à formiga $(23,66 \%)$ e adubação $(22,14 \%)$; e à manutenção, como: capina e, ou, roçada $(2,29 \%)$, controle de cupim $(0,76 \%)$, aceiros $(0,76 \%)$ e manejo florestal $(0,76)$. Para as demais fases do reflorestamento, nenhuma informação foi mencionada.

Quando questionados sobre a necessidade de assistência técnica ao reflorestamento, apenas $31,75 \%$ dos entrevistados responderam afirmativamente. Observou-se que quanto maior a propriedade, maior o interesse do agricultor pela assistência técnica florestal, o que pode significar uma visão mais lucrativa da atividade por parte dos agricultores dos estratos III e IV.

Essa necessidade de assistência técnica mostrou-se maior na fase de implantação do povoamento e menor na fase de colheita. Outro grande interesse despertado foi pela comercialização dos produtos florestais, principalmente nas propriedades do estrato IV.

Perguntados sobre futuras informações técnicas sobre a atividade florestal, apenas $25,40 \%$ dos entrevistados mostraram-se interessados. Como respostas mais freqüentes destacam-se: informações sobre a cultura de eucalipto $(17,65 \%)$, e espécies florestais adequadas à região $(17,65 \%)$; seguidas de informações sobre tratamento de madeira (mourões) $(11,76 \%)$ e combate à formiga e cupim $(11,76 \%)$. Outras respostas, com apenas uma citação $(5,88 \%)$, foram: manejo florestal, cultura de pinus, preparo do terreno para o reflorestamento, cultura de cedro, recomposição da mata nativa, legislação ambiental e alternativas de uso da madeira de eucalipto.

\section{CONCLUSÃO}

Como principais conclusões do estudo, citam-se:

- Muitos proprietários rurais do município encontramse descapitalizados e impossibilitados de ter acesso ao crédito rural, não aproveitando a capacidade produtiva das propriedades e relegando a agricultura praticada à condição de subsistência.

- O reflorestamento é tido como atividade pouco lucrativa por muitos agricultores, sendo relegado a segundo plano, motivo pelo qual não foram identificadas propriedades tipicamente florestais.

- A Universidade Federal de Viçosa, através da renda proporcionada aos seus funcionários, exerce grande influência econômica sobre o município, fazendo com que muitas das propriedades rurais sejam utilizadas para outras finalidades além daquelas produtivas, como lazer e recreação. Portanto, tais propriedades podem não ser representativas para a região.

- A aplicação de questionário em propriedades rurais pode, muitas vezes, ser subjetiva, pois os proprietários nem sempre têm pleno conhecimento sobre custos, rendimentos, níveis de produtividade, além de ficarem inibidos e não emitirem informações precisas. Neste sentido, a metodologia utilizada mostrou-se deficiente para alguns parâmetros considerados, quando foi exigida maior precisão para as estimativas.

- Os estratos I e II atendem à legislação florestal quanto à exigência da reserva legal, enquanto os demais extratos (III e IV) estão em desacordo com a lei.

- Os plantios florestais concentram-se nas áreas de encostas, principalmente no terço superior, pouco competindo, em área, com a produção de alimentos, que tradicionalmente são cultivados nas áreas mais planas.

- As políticas públicas de incentivo ao reflorestamento constituem uma ferramenta eficaz de proteção do meio ambiente; portanto devem ser encorajadas. 


\section{AGRADECIMENTO}

Os autores agradecem o apoio financeiro do $\mathrm{CNPq}$ e da FAPEMIG; e aos agricultores entrevistados e ao Instituto Estadual de Florestas (IEF-MG), pela contribuição para a realização deste trabalho.

\section{REFERÊNCIAS BIBLIOGRÁFICAS}

BRASIL. Leis, Decretos, etc. Decreto Lei No 4.771, de 15 de setembro de 1965. Código Florestal Brasileiro. Diário Oficial da República Federativa do Brasil, Brasília, 16 de set. 1965 .

COELHO, D. J. S. Modelo de gestão florestal sustentável para a microrregião de Viçosa, Minas Gerais. 1999. $80 \mathrm{f}$. Dissertação (Mestrado em Ciência Florestal) - Universidade Federal de Viçosa, Viçosa, 1999.

COSTA, E. B.; LOSS, W. R.; BARBOSA, C. A. Análise comparativa da competitividade econômica do eucalipto em relação às explorações tradicionais de café e pecuária no Estado do Espírito Santo - estudo de caso do programa fomento florestal da Aracruz Celulose S.A. Vitória: SEAG-ES, 1998. 54 p.

FONTES, A. A. Caracterização das propriedades rurais do município de Viçosa-MG com ênfase na atividade florestal. 2001. 115 f. Dissertação (Mestrado em Ciência Florestal) - Universidade Federal de Viçosa, Viçosa, 2001.

\section{GEOPROCESSAMENTO EM MINAS GERAIS -}

GEOMINAS. Programa integrado de uso da tecnologia de geoprocessamento pelos órgãos do Estado de Minas Gerais: dados sobre Minas. [S.I.]: PRODEMGE, 1996. Disponível em <http://www.geominas.mg.gov.br/>. Acesso em 03/05/ 2000 .
GONÇALVES, A. P. Estudo da questão florestal no Município de Viçosa. 1959. 199 f. Tese (Concurso para Provimento Efetivo da Cátedra de Silvicultura Geral e Espacial) - Universidade Rural do Estado de Minas Gerais, Viçosa, 1959.

LITTLE, A. D. Auditoria de meio ambiente, saúde ocupacional e segurança industrial: fundamentos, habilidades e técnicas. São Paulo: Arthur D. Little, 1997. 270 p. não publicado.

LÓPEZ, J. C. F. Análise do consumo e estratégia de sustentabilidade da lenha para uso doméstico em Cachoeira de Santa Cruz, Viçosa - MG, Brasil. 1999. 95 f. Dissertação (Mestrado em Ciência Florestal) Universidade Federal de Viçosa, Viçosa, 1999.

MINAS GERAIS. Lei florestal de Minas Gerais - Lei 10.561, de 27 de dezembro de 1991 - decreto de regulamentação com alterações introduzidas pela Lei 11.337, de 21 de dezembro de 1993. Belo Horizonte: IEF, 1995. $26 \mathrm{p}$.

PEREIRA, R. A. Mapeamento e caracterização de fragmentos de vegetação arbórea e alocação de áreas preferenciais para sua interligação no município de Viçosa, MG. 1999. 203 f. Tese (Doutorado em Ciência Florestal) - Universidade Federal de Viçosa, Viçosa, 1999.

SCHETTINO, L. F. Diagnóstico da situação florestal do Espírito Santo, visando estabelecer um plano de gestão sustentável. 2000. $174 \mathrm{f}$. Tese (Doutorado em Ciência Florestal) - Universidade Federal de Viçosa, Viçosa, 2000.

SOCIEDADE BRASILEIRA DE SILVICULTURA - SBS. Estatísticas. Disponível em <http://www.ipef.br/sbs/ estatisticas/>. Acesso em 27/10/2000. 